\title{
Emerging perspectives on hereditary glomerulopathies in canines
}

This article was published in the following Dove Press journal:

Advances in Genomics and Genetics

15 April 2015

Number of times this article has been viewed

\section{Meryl P Littman}

Department of Clinical Studies Philadelphia, University of Pennsylvania School of Veterinary Medicine, Philadelphia, PA, USA
Correspondence: Meryl P Littman Department of Clinical Studies Philadelphia, University of Pennsylvania School of Veterinary Medicine, 3900 Delancey Street, Philadelphia, PA 19104-6010, USA

$\mathrm{Tel}+\mathrm{I} 2158989288$

Fax +I 215 5736050

Email merylitt@vet.upenn.edu
Abstract: Familial glomerulopathies have been described in more than two dozen dog breeds. These canine spontaneous cases of glomerular disease are good models for their human counterparts. The dogs present clinically with protein-losing nephropathy and variable signs of hypertension, thromboembolic events, edema/effusions/nephrotic syndrome, or eventually with signs of renal disease such as anorexia, vomiting, weight loss, and/or polyuria/polydipsia. Laboratory changes include proteinuria, hypoalbuminemia, hypercholesterolemia, and eventually azotemia, hyperphosphatemia, anemia, and isosthenuria. Renal biopsies examined with transmission electron microscopy, immunofluorescence, and thin section light microscopy may show ultrastructural glomerular basement membrane abnormalities, glomerulosclerosis, amyloidosis, non-amyloid fibrillary deposition, or breed-associated predispositions for immunecomplex glomerulonephritis. Genome-wide association studies and fine sequencing of candidate genes have led to the discovery of variant alleles associated with disease in some breeds; eg, 1) glomerular basement membrane ultrastructural abnormalities due to defective collagen type IV, caused by different premature stop codons in each of four breeds; ie, in COL4A5 in Samoyeds and Navasota mix breed dogs (X-linked), and in COL4A4 in English Cocker Spaniels and English Springer Spaniels (autosomal recessive); and 2) glomerulosclerosis-related podocytopathy with slit diaphragm protein anomalies of both nephrin and Neph3/filtrin due to nonsynonymous single nucleotide polymorphisms in conserved regions of their encoding genes, NPHS1 and KIRREL2, in Soft Coated Wheaten Terriers and Airedale Terriers, with a complex mode of inheritance. Age at onset and progression to end-stage renal disease vary depending on the model. Genetic counseling using DNA testing is available for several breeds but many more inherited canine models of glomerulopathy still need to be characterized. Dog breeds, with their long haplotypes and linkage disequilibrium, represent excellent models to study the underlying molecular basis for protein-losing nephropathy, glomerular function, genetic manipulations, possible environmental triggers, and treatments. Results of studies of genetic canine diseases will help dogs and other species, including man.

Keywords: Alport, glomerulosclerosis, glomerulonephritis, nephrin, NPHS1, podocytopathy

\section{Introduction}

Veterinarians have long been diagnosing and managing pet dogs with spontaneous protein-losing nephropathy (PLN). ${ }^{1}$ The first sign of glomerular disease, persistent proteinuria, may be occult initially, but eventually discovered along with hypoalbuminemia, hypercholesterolemia, and possibly azotemia, hyperphosphatemia, anemia, and/or isosthenuria, when dogs present with clinical signs due to progressive renal injury (decreased appetite, weight loss, vomiting, polyuria/polydipsia [PU/PD]) or perhaps earlier with dramatic signs due to hypertension (eg, blindness due to retinal 
detachment or hemorrhage), thromboembolic events (eg, dyspnea or sudden death due to a pulmonary event, or hind leg lameness due to a distal aortic "saddle" thrombus), or nephrotic syndrome (eg, cavitary effusions or edema). If the owner allows, diagnostic tests are done to localize proteinuria to the kidney, search for any underlying cause, and plan a management regime. ${ }^{1-6}$ Standard treatment of canine PLN includes angiotensin-converting enzyme (ACE) inhibitors (and possibly other inhibitors of the renin-angiotensinaldosterone system), modified low protein/low phosphorus diets, antithrombotics, antihypertensives, omega-3 fatty acid supplementation, and treatments as needed for renal failure. ${ }^{3}$ Immunosuppressive protocols are recommended for PLN cases with an immune-mediated basis. ${ }^{4-6}$

In some instances the owner/breeder knows of similarly affected canine relatives. Pedigree analysis and banked DNA samples from sick dogs and their relatives have been very useful for study. More than two dozen breeds have shown familial PLN, ${ }^{1,7}$ but only recently, with the advent of better tools to define genotypes and better characterize phenotypes, have specific genetic abnormalities been identified and associated with specific pathologic entities. Genomic tools include databases and computer software to compare the whole canine genome sequence (map) with that of humans, genome-wide association studies (GWAS) with single nucleotide polymorphism (SNP) chip technology, and fine mapping (gene sequencing) of candidate genes using DNA extracted from blood, semen, or tissue samples from welldocumented affected animals and properly identified unaffected controls from the same genetic population. Phenotypic characterization of canine PLN subgroups is described with more accuracy currently by diagnostic testing to identify and localize proteinuria and to exclude acquired infectious, toxic, immune-mediated, and neoplastic causes of glomerular disease. ${ }^{1,6}$ Cortical renal samples (surgical wedge or percutaneous ultrasound-guided needle-core biopsies) may now be obtained from properly chosen candidates by trained personnel, submitted properly in special media, and interpreted by experienced veterinary nephropathologists using transmission electron microscopy (TEM), immunofluorescence (IF), and thin section $(3 \mu \mathrm{m})$ light microscopy (LM), in order to better define the ultrastructural detail of the glomerular basement membrane (GBM) and foot processes, visualize distinctive changes in cells and the extracellular matrix, and to check for the presence of amyloid, non-amyloid, and/or immunecomplex deposits. ${ }^{8}$ Previously, using LM and standard $5 \mu \mathrm{m}$ (thickly cut) sections, changes of glomerulosclerosis, glomerulonephritis, and GBM structural abnormalities had similar appearance, but with the introduction of more detailed examinations by TEM, IF, and thin section $(3 \mu) \mathrm{LM}$ and with special stains, veterinary nephropathologists are now able to differentiate these entities. Among 501 proteinuric field cases studied by TEM/IF/LM, ${ }^{9} 48 \%$ had immune-complex glomerulonephritis (ICGN), 21\% had primary glomerulosclerosis (focal segmental glomerulosclerosis [FSGS]), 15\% had amyloidosis, 9\% had non-immune complex glomerulopathy, 5\% had non-immune complex nephropathy, and $2 \%$ had primary tubular disease. Of these 501 cases, $47 \%$ were from just 12 dog breeds, most of which are suspected of having a genetic predisposition for PLN or renal disease, including Labrador Retrievers (10.4\%), Golden Retrievers (7.6\%), Yorkshire Terriers (5.8\%), Beagles (3.0\%), Miniature Schnauzers (3.0\%), Shetland Sheepdogs (2.8\%), Boxers (2.6\%), Dobermans (2.6\%), Cocker Spaniels (2.6\%), Soft Coated Wheaten Terriers (SCWT) (2.6\%), English Bulldogs $(2.2 \%)$, and Standard Poodles $(2.0 \%)$.

Once a phenotypic entity is well-defined, a search on the Online Mendelian Inheritance in Man resource at http://www. ncbi.nlm.nih.gov/pubmed/ may indicate possible candidate genes associated with that phenotype. If the phenotypic disorder or syndrome is complex, possibly involving a wide variety of pathogenetic mechanisms involving basic biochemical and/or physiologic pathways with a myriad of candidate genes, the field of study may be narrowed by comparing genomes of affected cases with related unaffected control/geriatric cases via GWAS, to search for statistically significant differences of linked SNPs, pointing to intervals of interest on one or more chromosomes, containing fewer candidate genes for study.

A GWAS may find linked markers (SNPs) and one or more candidate genes within an interval which may be associated with risk for affectation. Gene sequencing of candidate genes from affected and control dogs may show that a mutation exists, such as a deletion, addition, or even a single non-synonymous SNP that is associated with affectation. The identification of a variant allele of a candidate gene associated with the trait (PLN) proposes that the underlying molecular basis and pathogenesis for the phenotype includes alteration of the encoded protein, whose impact may be predicted by PolyPhen-2 software. Understanding the pathogenesis may suggest specific treatment. Customized Taqman genotyping assays (Illumina Inc., San Diego, CA, USA) for the discovered variant allele may then be developed as a "DNA test" to help identify individuals at risk for disease, in order to closely monitor them and initiate intervention earlier to hopefully slow disease progression, and to help breeders 
identify which dogs are best to breed with one another to decrease the production of dogs at risk, while maintaining genetic diversity in the breed, through genetic counseling. Different breeds with similar phenotypes often have different mutations in either the same gene or a different gene, unless the breeds have common ancestral backgrounds; therefore different DNA tests may be necessary to detect at-risk variant allele carrier status in each breed. For human patients, up to 37 PLN candidate genes, including those associated with either Alport syndrome or FSGS, or even 292 genes associated with kidney malformations, may be studied at the same time, by next-generation sequencing and targeted exome sequencing, which may find novel mutations in a family. ${ }^{10-15}$ Such comprehensive panels are species-specific, and development of platforms to capture and evaluate canine exons of these candidate genes is needed.

The development of canine breeds led to their extensive linkage disequilibrium and long haplotypes, ${ }^{16}$ making them excellent models for genetic research because relatively few affected cases and controls may yield statistically significant findings. A spontaneous canine model of PLN may genuinely mimic spontaneous disease in man, with similar signs of illness, laboratory and histopathologic changes, and response to medications and diets. In addition, pet dogs which live closely with people are exposed to similar environmental triggers and may have similar comorbidities which realistically portray the nature of complex disease.

\section{Canine models of GBM defects: collagen IV abnormalities}

The distinctive ultrastructural GBM abnormalities found in some models ${ }^{17}$ of canine PLN (ie, extensive longitudinal multilaminar splitting and thickening of the GBM with a basketweave appearance in the lamina densa) and abnormal collagen IV chain content in the GBM, found by immunohistochemical staining with antibodies directed against specific chains, led investigators to sequence the candidate genes involved in human Alport syndrome in these canine cases. Since dogs do not show Alport-associated hearing deficits or ocular changes, the term "hereditary nephropathy" (HN) is used. ${ }^{17}$

Collagen IV is the main structural component of the framework of the GBM which is important for the permselective barrier. Abnormal production, assembly, and repair of the GBM causes proteinuria and then further adaptive changes damage the rest of the nephron (glomerulus and tubules), leading to progressive damage, azotemia, PU/PD, and end-stage renal disease (ESRD). Collagen IV is made up of heterotrimers of six possible collagen chains, numbered $\alpha 1$ through $\alpha 6$, encoded by genes COL4A1 through COL4A6. COL4A1 and COL4A2 are on canine chromosome 22, COL $4 A 3$ and COL4A4 are on chromosome 25, and COL $4 A 5$ and $C O L 4 A 6$ are on the canine $\mathrm{X}$ chromosome. In mature mammalian kidneys, the heterotrimer that is predominant in the GBM is $\alpha 3 \alpha 4 \alpha 5$; the chains need to cross-link into a network via sulfilimine bonds of adjacent conserved methionine and lysine residues. ${ }^{10} \mathrm{~A}$ short or abnormally folded chain that cannot cross-link properly in the network would interfere with the 3-dimensional nanostructure of this important network and cause the laminar splitting that is seen ultrastructurally by TEM. The main candidate genes to investigate in dogs with suspected HN are COL $4 A 5$ (for an X-linked mode of inheritance) and COL $4 A 3$ and COL $4 A 4$ (for an autosomal mode of inheritance).

In 1994, the first characterization of the genetic basis for an inherited canine glomerulopathy was described in Samoyed dogs. ${ }^{17-19}$ The mode of inheritance is X-linked; affected hemizygous males show proteinuria quite early (3-6 months of age) and progress to ESRD by 6-24 months of age. Heterozygous carrier female Samoyeds (mosaics) also show proteinuria early but typically do not show ESRD until past 5 years of age. Ultrastructural GBM changes suggested HN, and as an X-linked form of HN (XLHN), a $C O L 4 A 5$ mutation was suspected, further supported by immunostaining with monoclonal anti- $\alpha 5$ antibodies which showed decreased $\alpha 5$ chains present in the GBM of affected dogs compared with controls. Upon sequencing the gene COL4A5, a non-synonymous SNP was found in exon 35, changing a $\mathrm{G}$ to a $\mathrm{T}(\mathrm{c} .3079 \mathrm{G}>\mathrm{T})$, causing a premature stop codon and truncated $\alpha 5$ chain. An allele-specific polymerase chain reaction (PCR) test for this mutation is available (http:// www.vetgen.com; http://www.pawprintgenetics.com) thus carrier dogs are removed from the gene pool, curtailing PLN among pet Samoyed dogs.

Another model of XLHN was found in a family of mix breed dogs from Navosota, TX..$^{20,21}$ In these dogs, carriers of both sexes show early onset of proteinuria by 6 months and ESRD at 6-18 months of age. Sequencing of the COL4A5 gene showed a 10 base-pair deletion in exon 9 (c.689_699delTAATCCAGGA) which caused a frame shift and a premature stop codon in exon 10 in this dominant form of XLHN. It is not unusual to find different mutations associated with the same phenotype. In humans, more than 1,100 unique variants have been found in $C O L 4 A 5$, of which $40 \%$ are missense and 50\% nonsense mutations. ${ }^{10}$ Glycine substitutions occur most frequently; Gly-X-Y is an important 
repeating triplet in the triple chain helical structure of collagen in the GBM. ${ }^{10}$

The generation of closed colonies of XLHN carrier and affected dogs has been an important resource for study. ${ }^{17}$ These models have been useful to study microalbuminuria development, ${ }^{22}$ daily variation of proteinuria, ${ }^{23}$ urinary biomarkers, ${ }^{24,25}$ the development of the GBM network from fetal $(\alpha 1 \alpha 1 \alpha 2)$ to adult type $(\alpha 3 \alpha 4 \alpha 5)$ collagen IV, ${ }^{26}$ and the effects of ACE inhibition, ${ }^{27}$ prednisone, ${ }^{28}$ diet, ${ }^{29,30}$ and cyclosporine ${ }^{31}$ on this model.

From the mid-1940s until 2007 when a DNA test was developed, English Cocker Spaniels were at risk for "familial nephropathy" and ESRD by 10-24 months of age..$^{32-35}$ The autosomal recessive mode of inheritance made it difficult to eradicate, as normal appearing heterozygote carrier matings occurred. It was not until TEM was utilized that affected dogs (but not carriers) were found to have GBM changes of $\mathrm{HN}$, and an autosomal mutation in either COL4A3 or COL4A4 was suspected. ${ }^{34}$ When sequenced, a COL4A4 non-synonymous SNP was found in exon 3, changing an $\mathrm{A}$ to a $\mathrm{T}(\mathrm{c} .115 \mathrm{~A}>\mathrm{T})$, causing a premature stop codon. The allele-specific PCR DNA test (http://www.optigen.com) allows breeders to avoid breeding normal appearing carrier heterozygotes to one another and thus decrease the production of this autosomal recessive disease.

Most recently another autosomal recessive form of $\mathrm{HN}$ was found in two female English Springer Spaniel littermates at 7 months of age, which progressed to ESRD over 2-3 months. The mutation found was a non-synonymous SNP in exon 30 of COL4A4, changing $\mathrm{C}$ to $\mathrm{T}(\mathrm{c} .2712 \mathrm{C}>\mathrm{T})$, causing a premature stop codon. ${ }^{36} \mathrm{~A}$ specific $\mathrm{PCR}$ test is available (http://www.pawprintgenetics.com).

Bull Terriers ${ }^{17,37-40}$ and Dalmatians ${ }^{41}$ appear to have autosomal dominant forms of $\mathrm{HN}$, which as in their human counterparts, may show clinical variability. ${ }^{42}$ Onset of ESRD is variable and can be later in life, up to 10 years of age (much later than the XLHN models above) with an average age of onset for Bull Terriers at 3.5 years (range 11 months to 8 years) and for Dalmatians at 18 months (range 8 months to 7 years). Although the mode of inheritance is dominant, normal appearing dogs might be bred unknowingly. With no genetic test available, conscientious breeders screen for proteinuria using microalbuminuria or urine protein/creatinine (UPC) ratio tests to identify dogs at risk (UPC $\geq 0.3$ ) as early as possible and to start early intervention which may slow progression. Studies in Bull Terriers showed that although the GBM appears as HN by TEM examination (already seen in stillborn and 1-day old pups, compared with 1 month of age in the XLHN model), immunostaining showed normal amounts of collagen IV chains. Functional defects, perhaps due to non-synonymous SNPs, or other genes such as MYH9 or $L M X 1$ may be involved. ${ }^{17}$ Ultrastructural GBM changes suggestive of HN may also be seen in other breeds for which the specific genetic defects still need to be characterized, eg, Doberman Pinschers ( $<3$ years) ${ }^{43}$ Beagles (up to at least 8 years $),{ }^{44}$ and Rottweilers $(<1$ year $) .{ }^{45}$

\section{Canine models of podocytopathy and glomerulosclerosis associated with NPHSI and KIRREL2 variant alleles SCWT}

Breeders of SCWT dogs in North America recognized in the 1980 s that too many dogs $(10 \%-15 \%)^{46}$ were sick or dying prematurely in young to middle-aged adulthood, many with similar clinical signs (vomiting, diarrhea, hyporexia, weight loss, effusions, PU/PD, sometimes sudden death) and laboratory abnormalities (hypoproteinemia, azotemia, low $\mathrm{Na}^{+} /$ $\mathrm{K}^{+}$ratio), which were eventually differentiated as separate or combined renal, intestinal, and/or adrenal diseases, based on blood, urine, and histopathology results. An SCWT DNA bank at the University of Pennsylvania School of Veterinary Medicine (PennVet) began to store hundreds of samples from affected SCWT dogs as well as geriatric (14-18 years old) unaffected relatives. Beginning in 1997, the SCWT Open Registry listed dogs documented to have PLN (n=722 last update), protein-losing enteropathy (PLE) or inflammatory bowel disease (IBD) $(\mathrm{n}=501)$, combined PLE/PLN ( $\mathrm{n}=279)$, Addison's disease ( $\mathrm{n}=98)$, and juvenile renal disease (JRD), also known as renal dysplasia ( $\mathrm{n}=66$ ). Many dogs had combined affectation, due to the small foundation stock brought from Europe and popular sires, or a shared molecular pathogenesis. Dogs with PLN had proteinuria, hypoalbuminemia, and hypercholesterolemia, with or without hypertension, thromboembolic events, effusions, or azotemia. PU/PD was a late development associated with secondary tubular damage, as opposed to an early finding in dogs with JRD. Dogs with PLE often had small bowel diarrhea, possibly with effusions or thromboembolic events, and had panhypoproteinemia and hypocholesterolemia. The age of onset was $4.7 \pm 2.6$ years for PLE, 5.9 \pm 2.2 years for PLE/PLN, and 6.3 \pm 2.0 years for PLN, but there was no age limit. ${ }^{46}$ The mode of inheritance of PLE/PLN appeared complex; the Open Registry listed affected dogs with long-lived ancestors (suggesting recessive inheritance), but the "Wheagle" colony at the North 
Carolina State University College of Veterinary Medicine (developed by breeding an affected SCWT with a Beagle) produced affected dogs in the first generation, suggesting dominant inheritance. ${ }^{47}$ In field cases, PLE and/or PLN were reported in more female than male dogs (female:male $=1.4-1.9$ ) however sampling bias may exist because breeders own more females. ${ }^{46}$ The pathogenesis of the diseases was unclear; renal histopathology (usually only examined by LM after death) showed changes consistent with glomerulosclerosis or glomerulonephritis and intestinal biopsies showed lymphocytic-plasmacytic IBD and/or lymphangiectasia. ${ }^{46,48}$ Some renal samples examined by TEM, IF, and LM in colony dogs showed glomerulosclerosis in $10 \%$ of glomeruli and immune-deposits in $4 \%,{ }^{49}$ but whether these were causative or passive findings was unknown. There were no early biomarkers to warn of future PLE/PLN in young dogs or breeding stock and many dogs were bred before affectation was apparent. This model of PLN was used to study the onset of microalbuminuria ${ }^{50}$ and that averaging a pooled sample over several days was a useful method to determine daily proteinuria by UPC ratio determinations, in view of daily variation. ${ }^{51}$

The main theories of pathogenesis for PLN in SCWT included 1) immunodysregulation, in view of possible breedassociated ICGN, ${ }^{46,48,49}$ food allergies, IBD, or PLE, ${ }^{46,52,53}$ presence of pANCA antibodies, ${ }^{54,55}$ possible female predisposition, ${ }^{46}$ and Addison's disease (which may have an immune-mediated basis); and 2) possibly structural, functional, growth/repair factors, or developmental abnormalities causing intestinal, renal, or lymphatic/vascular cell adhesion defects, permeability changes, and loss of proteins, glomerulosclerosis, intestinal lymphangiectasia, ${ }^{46}$ and/or JRD with fetal glomeruli and fetal mesenchyme. ${ }^{56-58}$ In other words, there were too many possible gene candidates needing to be sequenced.

In order to narrow the field of study, a GWAS was done at PennVet, ${ }^{59}$ which revealed a significantly different region in PLN-affecteds $(n=42)$ compared to related geriatric controls $(n=20)$ on canine chromosome 1 , with three statistically significant SNPs $\left(\mathrm{p}_{\text {raw }} \leq 4.13 \times 10^{-8}, \mathrm{p}_{\text {genome }} \leq 0.005\right)$ in a region encompassing 65 genes, four of which were considered candidate genes for PLN, based on Online Mendelian Inheritance in Man resources. Fine mapping of the four candidate genes showed novel variant alleles in two of them, NPHS1 and KIRREL2, which are in linkage disequilibrium. These genes encode two cell adhesion proteins of the immunoglobulin superfamily, nephrin and Neph3/filtrin, which are part of the complex nanostructure in the slit diaphragm between the podocyte foot processes. Each gene showed a single nonsynonymous SNP not found in other species, associated with PLN in SCWT. Nephrin is the major slit diaphragm protein, and more than 176 different mutations in NPHS1 have been found associated with PLN in people, including infantile, juvenile, and adult-onset forms. No mutations in KIRREL2 are known yet but decreased expression of Neph3/filtrin has been associated with PLN in people. In SCWT with PLN, in exon 22 of NPHS1, G is changed to A (c.3067G>A), altering a glycine residue (conserved among mammals) to an arginine (G1023R), in the FN3 domain of nephrin. In exon 15 of KIRREL2, C is changed to $\mathrm{G}$ (c.1877C $>\mathrm{G})$, changing a proline residue in a conserved proline-rich interval to an arginine (P626R). The application of PolyPhen-2 software showed the SCWT NPHS1 variant is "probably damaging" (the highest score) and the KIRREL2 variant is "possibly damaging" (next highest score).

An additional 145 SCWT dogs with known phenotypes were tested for these SNPs, using a customized Taqman assay for the PLN-associated variant alleles. ${ }^{59}$ Homozygous positive dogs showed the highest risk, heterozygous dogs showed intermediate risk, and homozygous negative dogs showed lowest risk for development of PLN $(2 \times 3$ contingency table, $\left.P=7.78 \times 10^{-10}\right)$ in their lifetimes. The odds ratio for affectation was 29.5 (homozygous positive versus [vs] homozygous negative), 6.8 (homozygous positive vs heterozygous), and 9.1 (homozygous positive vs others).

When non-SCWT breeds were tested for these NPHS1 ( $\mathrm{n}=747$ dogs of 114 breeds) and KIRREL2 ( $\mathrm{n}=550$ dogs of 105 breeds) variant alleles, only three dogs showed these SNPs, including two Airedales (one was homozygous positive for both SNPs and died of PLN, and one was heterozygous for both SNPs) and one Bloodhound, which was heterozygous for the KIRREL2 SNP only. ${ }^{59}$

A worldwide prevalence study ${ }^{60}$ of 1,208 samples $(\mathrm{n}=2,166$ most recently) from SCWT of North America, Europe, and Australia, showed 45\% (43\%) of the dogs are heterozygous, 38\% (42\%) are homozygous negative, and $17 \%(15 \%)$ are homozygous positive for both variant alleles. The variant allele frequency in the breed is high (40\%; recently $37 \%$ ), therefore culling all carriers would lead to loss of genetic diversity and possibly new genetic diseases. The current recommendation is to test dogs (http://www.scwtca.org/health/dnatest.htm) to know an individual's risk for developing PLN in its lifetime, and to choose mates for dogs in order to avoid producing homozygous positive puppies. Homozygous positive or heterozygous dogs are best bred to homozygous negative 
dogs, to reduce variant allele frequency over time and decrease risk for PLN.

Although retrospective studies show a high statistically significant relationship of the PLN-associated variant alleles with disease, not all homozygous positive dogs become affected. The mode of inheritance of PLN in SCWT is complex, possibly with multiple genes, variable expression, incomplete penetrance, and/or environmental triggers. Prospective studies need to be done to see what percentage of dogs with each haplotype become affected, and to study whether modifier genes, comorbidities, or environmental triggers may be involved with expression of phenotype. While the predominant histopathologic lesion appears as varying degrees of FSGS, likely due to genetic podocytopathy and slit diaphragm protein defects, it may be that podocytes of affected SCWT are weakened and susceptible to further damage by inflammation or circulating immune complexes which otherwise normal dogs are able to process. ${ }^{48}$ Many SCWT have food allergies, IBD, or PLE, and since dogs with combined PLE/PLN average higher UPC than dogs with PLN alone ${ }^{46}$ the clinical expression of PLN in carriers may be exacerbated by a multiple hit pathogenesis.

\section{Airedale Terriers}

Given that two Airedale Terrier carriers were found in SCWT studies, including one homozygous positive dog which had PLN, and that some breeders noticed familial renal disease as a problem, a broader North American Airedale Terrier prevalence study was done, which showed a variant allele frequency of $28 \%$ among 221 dogs. ${ }^{61}$ Recent statistics for 297 Airedale Terriers found $47 \%$ were homozygous negative, $44 \%$ were heterozygous, and $9 \%$ were homozygous positive for the PLN-associated variant alleles (NPHS1 and KIRREL2) previously found in SCWT. A genotype-phenotype correlation study has not yet been done for lack of samples from Airedales with well-characterized phenotypes. However, among 24 dogs closely related to Airedale Terriers that had died with kidney disease (but which themselves were not available for testing), the allele frequency was higher than in the general Airedale population ( $42 \%$ vs $28 \%$ ), suggesting that the presence of these variant alleles is associated with risk for kidney disease in Airedale Terriers, as in the SCWT breed.

\section{Abnormal glomerular deposition Collagen III}

A family of mix breed dogs with PLN was found to have collagenofibrotic glomerulonephropathy. ${ }^{62,63}$ Test matings indicated an autosomal mode of inheritance. As in humans, increased serum levels of the amino-terminal propeptide of type III procollagen (PIIINP) may be used as a marker of this defect. Hypocomplementemia, found in a few human cases, was not observed in the canine model. The COL3A1 gene did not appear to be involved in dogs. A similar abnormal glomerular deposition of collagen III fibrils in glomeruli may have been found in Newfoundland ${ }^{64}$ dogs but needs more study.

\section{Amyloidosis}

Familial amyloidosis in Chinese Shar Pei,${ }^{65-67}$ Beagle, ${ }^{68}$ and English Foxhound ${ }^{69}$ breeds is seen with adult onset. Amyloid deposition affecting glomeruli causes PLN. In Shar Pei, deposition of amyloid AA is probably due to chronic inflammatory disease and the fever/hock syndrome, a common comorbidity, due to an unstable duplication of the HAS2 gene that causes wrinkling and periodic fever syndrome. ${ }^{67}$

\section{Immune-complex deposition}

Labradors and Golden Retrievers and possibly Shetland Sheepdogs show a predisposition for Lyme-specific ICGN, known as "Lyme nephritis"., 6,70-74 Possibly an unidentified genetic podocytopathy or immunodysregulatory defect triggers abnormal immune complex handling, since most Lymeseropositive dogs, even among these predisposed breeds, do not show proteinuria or Lyme nephritis. Bernese Mountain Dogs, ${ }^{75-78}$ found to be more likely Lyme-seropositive than other breeds with the same lifestyle, were originally thought to have a predisposition for Lyme nephritis, however their Lyme-seropositive status is not associated with proteinuria or lameness and their membranoproliferative glomerulonephritis is familial with an autosomal recessive mode of inheritance possibly with an X-linked modifier gene, affecting mostly females (female:male $=4$ ). Other breeds at risk for ICGN because of a higher risk for associated infectious diseases or drug sensitivity are American Foxhounds (Leishmaniasis), ${ }^{79-82}$ Basenjis (IBD/PLE), ${ }^{83}$ Doberman Pinschers (sulfonamides), ${ }^{84-86}$ German Shepherds (Ehrlichia canis), ${ }^{87-90}$ and SCWT (IBD/PLE) ${ }^{46-60}$ A colony of Brittany Spaniel dogs was found to have type 1 membranoproliferative glomerulonephritis secondary to complement C3 deficiency, due to a deletion mutation in the gene encoding C3. ${ }^{91,92}$

\section{More breeds with familial glomerulopathies}

Other breeds with familial glomerulopathies that need more characterization are listed in Table 1. Renal proteinuria may also be seen with familial nephropathies, not to be confused 
Table I Breed-associated glomerulopathies in dogs

\begin{tabular}{|c|c|c|}
\hline Phenotype and breeds & Gene defect, mode of inheritance* & Onset, other \\
\hline \multicolumn{3}{|c|}{ GBM defect of collagen IV hereditary nephritis (HN) ${ }^{17}$} \\
\hline English Cocker Spanie| ${ }^{32-35}$ & COL4A4, AR, c.II5A $>T$ & Juvenile \\
\hline English Springer Spaniel ${ }^{36}$ & COL4A4, AR, c. $2712 C>T$ & Juvenile \\
\hline \multirow[t]{2}{*}{ Navasota, TX mixbreed ${ }^{20,21}$} & COL4A5, X-linked, D & Juvenile \\
\hline & c.689_699delTAATCCAGGA & \\
\hline \multirow[t]{2}{*}{ Samoyed ${ }^{17-19}$} & COL4A5, X-linked, $R$ (mosaic) c.3079G $>T$ & Juvenile - males; females are also \\
\hline & & proteinuric but live longer \\
\hline \multicolumn{3}{|l|}{ Less characterized $\mathrm{HN}$} \\
\hline Beagle $^{44}$ & & Adult, possibly MPGN or GS \\
\hline Bull Terrier ${ }^{37-40}$ & $A D$ & Adult \\
\hline Dalmation ${ }^{41}$ & $A D$ & Juvenile-adult \\
\hline Rottweiler ${ }^{45}$ & & Juvenile \\
\hline \multicolumn{3}{|l|}{ Podocytopathy } \\
\hline Soft Coated Wheaten Terrier, Airedale & Nephrin/NPHSI, c.3067G $>$ A and & Adult GS, may also be predisposed to \\
\hline Terrier, Wheagle $\left(\mathrm{SCWT} \times\right.$ Beagle $^{46-61}$ & Neph3/filtrin/KIRREL2, c.I877C > G, CX & ICGN \\
\hline \multicolumn{3}{|l|}{ Glomerular depositions } \\
\hline \multicolumn{3}{|l|}{ Collagen III } \\
\hline Mixbreed ${ }^{62,63}$ & AR, COL3AI defect not found & Juvenile, collagenofibrotic glomerulopathy \\
\hline Newfoundland ${ }^{64}$ & $A R$ & Juvenile, as above \\
\hline \multicolumn{3}{|l|}{ Renal amyloidosis } \\
\hline Beagle $^{68}$ & & Adult \\
\hline Chinese Shar Pei ${ }^{1,65-67}$ & HAS2; g.23,746,089_23,762,189dup 16.1 kb & $\begin{array}{l}\text { Associated with periodic fever syndrome; } \\
\text { wrinkling gene }\end{array}$ \\
\hline English Foxhound ${ }^{69}$ & & Adult \\
\hline \multicolumn{3}{|l|}{ Immune complexes } \\
\hline American Foxhound ${ }^{79-82}$ & & Adult - Leishmaniasis \\
\hline Basenji $^{83}$ & & Adult - SIIPD \\
\hline Brittany Spaniel ${ }^{91,92}$ & C3, AR, c.2136delC & Adult - Complement deficiency \\
\hline Doberman $^{84-86}$ & & Adult - sulfa drugs \\
\hline German Shepherd ${ }^{87-90}$ & & Adult - Ehrlichia canis \\
\hline Golden Retriever ${ }^{70-74}$ & & Adult - Borrelia antigens \\
\hline Labrador Retriever ${ }^{70-74}$ & & Adult - Borrelia antigens \\
\hline Shetland Sheepdog ${ }^{70-74}$ & & Adult - Borrelia antigens \\
\hline Soft Coated Wheaten Terrier, & See podocytopathy above; the genetic basis & Adult - ICGN possibly associated with \\
\hline Wheagle ${ }^{46-60}$ & for IBD/PLE is unknown & $\mathrm{IBD} / \mathrm{PLE}$ \\
\hline \multicolumn{3}{|c|}{ Other breed-associated glomerulopathies } \\
\hline Bernese Mountain Dog ${ }^{75-78}$ & $A R \pm$ sex-linked modifier gene; female:male $=4$ & Adult, mesangiocapillary GN \\
\hline Bull Mastiff ${ }^{93}$ & $A R$ & Adult GS \\
\hline Doberman ${ }^{94}$ & & Cystic glomerulopathy \\
\hline French Mastiff95 & & Juvenile atrophic glomeruli; GS \\
\hline Greyhound $96-99$ & & Glomerular vasculopathy \\
\hline \multirow[t]{2}{*}{ Miniature Schnauzer ${ }^{100}$} & & Juvenile and adult, GS (possibly \\
\hline & & associated with JRD) \\
\hline Newfoundland ${ }^{64}$ & $A R$ & Juvenile, GS \\
\hline Norwegian Elkhound ${ }^{101-103}$ & & Juvenile-adult, periglomerular sclerosis \\
\hline Pembroke Welsh Corgi ${ }^{104}$ & & Juvenile, similar to Doberman \\
\hline Rottweiler 105 & Possibly less characterized HN, above & Juvenile, atrophic glomeruli \\
\hline
\end{tabular}

Note: *See http://www.wsava.org/HereditaryDefects.htm.

Abbreviations: A, autosomal; CX, complex; D, dominant; GBM, glomerular basement membrane; GN, glomerulonephritis; GS, glomerulosclerosis; HN, hereditary nephritis; IBD/PLE, inflammatory bowel disease/protein-losing enteropathy; ICGN, immune-complex glomerulonephritis; JRD, juvenile renal disease; MPGN, membranoproliferative glomerulonephritis; R, recessive; SIIPD, small intestinal immunoproliferative disease.

with glomerulopathies, including JRD in numerous breeds with altered renal development and distinctive fetal glomeruli/ mesenchyme, reflux nephropathy in Boxer and Gordon Setter dogs, autosomal dominant polycystic kidney disease in Bull Terriers (PKD1, c.9772G>A), ${ }^{106}$ Fanconi syndrome in Basenjis, polycystic disease in Cairn and West Highland White Terriers, multiple renal cystadenocarcinomas in German Shepherds, and telangiectasia in Pembroke Welsh Corgis. ${ }^{1,7}$ New reports of familial PLN are likely to occur due to inbreeding, small foundation stock, popular sires, and 
removal of carriers of other known diseases while trying to perpetuate breed characteristics. Mix breed dogs and their families are also at risk, since the modes of inheritance may be dominant or complex.

\section{Summary}

In summary, many canine breeds have inherited glomerulopathies which are models for human disease, including GBM defects analogous to Alport syndrome, FSGS, and abnormal glomerular depositions of collagen III, amyloid, or immune complexes. The underlying molecular basis is only known for some breeds, and many more need their genetic defects defined. With GWAS, fine sequencing, and the future development of candidate gene sequencing panels specifically developed for dogs, many more underlying genetic defects will be able to be determined. Screening followed by genetic counseling will help breeders produce fewer dogs carrying at-risk genes while maintaining genetic diversity. Awareness of these animal models may benefit investigators studying the molecular basis for disease, inheritance patterns, progression, and treatment options.

\section{Disclosure}

The author reports no conflicts of interest in this work.

\section{References}

1. Littman MP. Protein-losing nephropathy in small animals. Vet Clin North Am Small Anim Pract. 2011;41(1):31-62.

2. IRIS Canine GN Study Group Diagnosis Subgroup, Littman MP, Daminet S, Grauer GF, Lees GE, van Dongen AM. Consensus recommendations for the diagnostic investigation of dogs with suspected glomerular disease. J Vet Intern Med. 2013;27 Suppl 1:S19-S26.

3. IRIS Canine GN Study Group Standard Therapy Subgroup, Brown S, Elliott J, Francey T, Polzin D, Vaden S. Consensus recommendations for standard therapy of glomerular disease in dogs. J Vet Intern Med. 2013;27 Suppl 1:S27-S43.

4. IRIS Canine GN Study Group Established Pathology Subgroup, Segev G, Cowgill LD, Heiene R, Labato MA, Polzin DJ. Consensus recommendations for immunosuppressive treatment of dogs with glomerular disease based on established pathology. J Vet Intern Med. 2013;27 Suppl 1: S44-S54.

5. IRIS Canine GN Study Subgroup on Immunosuppressive Therapy Absent a Pathologic Diagnosis, Pressler B, Vaden S, Gerber B, Langston C, Polzin D. Consensus guidelines for immunosuppressive treatment of dogs with glomerular disease absent a pathologic diagnosis. J Vet Intern Med. 2013;27 Suppl 1:S55-S59.

6. IRIS Glomerular Disease Study Group, Goldstein RE, Brovida C, et al. Consensus recommendations for treatment for dogs with serology positive glomerular disease. J Vet Intern Med. 2013;27 Suppl 1:S60-S66.

7. Lees GE. Congenital kidney diseases. In: Bartges J, Polzin DJ, editors. Nephrology and Urology of Small Animals. Ames, IA: Wiley-Blackwell; 2011:568-576.

8. Cianciolo RE, Brown CA, Mohr FC, et al. Pathologic evaluation of canine renal biopsies: Methods for identifying features that differentiate immune-mediated glomerulonephritides from other categories of glomerular diseases. J Vet Intern Med. 2013;27 Suppl 1:S10-S18.
9. Schneider SM, Cianciolo RE, Nabity MB, Clubb FJ Jr, Brown CA, Lees GE. Prevalence of immune-complex glomerulonephritides in dogs biopsied for suspected glomerular disease: 501 cases (2007-2012). J Vet Intern Med. 2013;27 Suppl 1:S67-S75.

10. Miner JH, Baigent C, Flinter F, et al. The 2014 International Workshop on Alport Syndrome. Kidney Int. 2014;86(4):679-684.

11. Morinière $\mathrm{V}$, Dahan $\mathrm{K}$, Hilbert $\mathrm{P}$, et al. Improving mutation screening in familial hematuric nephropathies through next generation sequencing. J Am Soc Nephrol. 2014;25(12):2740-2751.

12. Brown EJ, Pollak MR, Barua M. Genetic testing for nephrotic syndrome and FSGS in the era of next-generation sequencing. Kidney Int. 2014;85(5):1030-1038.

13. Liapis H. Renal Pathology: SC23-1 Role of next generation sequencing (NGS) in the diagnosis of hereditary renal disease. Pathology. 2014;46 Suppl 2:S39-S40.

14. Webb BD, Brandt T, Liu L, et al. A founder mutation in COL4A3 causes autosomal recessive Alport syndrome in the Ashkenazi Jewish population. Clin Genet. 2014;86(2):155-160.

15. Chatterjee R, Hoffman M, Cliften P, Seshan S, Liapis H, Jain S. Targeted exome sequencing integrated with clinicopathological information reveals novel and rare mutations in atypical, suspected and unknown cases of Alport syndrome or proteinuria. PLoS One. 2013;8(10):e76360:1-9.

16. Ostrander EA. Both ends of the leash - The human links to good dogs with bad genes. $N$ Engl J Med. 2012;367(7):636-646.

17. Lees GE. Kidney diseases caused by glomerular basement membrane type IV collagen defects in dogs. J Vet Emerg Crit Care. 2013;23(2):184-193.

18. Zheng K, Thorner PS, Marrano P, Baumal R, McInnes RR. Canine X chromosome-linked hereditary nephritis: A genetic model for human $\mathrm{X}$-linked hereditary nephritis resulting from a single base mutation in the gene encoding the $\alpha 5$ chain of collagen type IV. Proc Natl Acad Sci U S A. 1994;91(9):3989-3993.

19. Jansen B, Valli VE, Thorner P, Baumal R, Lumsden JH. Samoyed hereditary glomerulonephropathy: Serial clinical and laboratory (urine, serum biochemistry and hematology) studies. Can JVet Res. 1987;61(3): 387-393.

20. Cox ML, Lees GE, Kashtan CE, Murphy KE. Genetic cause of X-linked Alport syndrome in a family of domestic dogs. Mamm Genome. 2003;14(6):396-403.

21. Lees GE, Helman RG, Kashtan CE, et al. New form of X-linked dominant hereditary nephritis in dogs. Am J Vet Res. 1999;60(3): 373-383.

22. Lees GE, Jensen WA, Simpson DF, Kashtan CE. Persistent albuminuria precedes onset of overt proteinuria in male dogs with X-linked hereditary nephropathy [abstract]. J Vet Intern Med. 2002;16(3):353.

23. Nabity MB, Boggess MM, Kashtan CE, Lees GE. Day-to-day variation of the urine protein:creatinine ratio in female dogs with stable glomerular proteinuria caused by X-linked hereditary nephropathy. J Vet Intern Med. 2007;21(3):425-430.

24. Nabity MB, Lees GE, Dangott LJ, Cianciolo R, Suchodolski JS, Steiner JM. Proteomic analysis of urine from male dogs during early stages of tubulointerstitial injury in a canine model of progressive glomerular disease. Vet Clin Pathol. 2011;40(2):222-236.

25. Nabity MB, Lees GE, Cianciolo R, Boggess MM, Steiner JM, Suchodolski JS. Urinary biomarkers of renal disease in dogs with X-linked hereditary nephropathy. J Vet Intern Med. 2012;26(2):282-293.

26. Harvey SJ, Zheng K, Sado Y, et al. Role of distinct type IV collagen networks in glomerular development and function. Kidney Int. 1998;54(6): 1857-1866.

27. Grodecki KM, Gains MJ, Baumal R, et al. Treatment of X-linked hereditary nephritis in Samoyed dogs with angiotensin-converting enzyme (ACE) inhibitor. J Comp Pathol. 1997;117(3):209-225.

28. Lees GE, Willard MD, Dziezyc J. Glomerular proteinuria is rapidly but reversibly increased by short-term prednisone administration in heterozygous (carrier) female dogs with X-linked hereditary nephropathy [abstract]. J Vet Intern Med. 2002;16(3):352. 
29. Valli VE, Baumal R, Thorner P, et al. Dietary modification reduces splitting of glomerular basement membranes and delays death due to renal failure in canine X-linked hereditary nephritis. Lab Invest. 1991;65(1):67-73.

30. Burkholder WJ, Lees GE, LeBlanc AK, et al. Diet modulates proteinuria in heterozygous female dogs with X-linked hereditary nephropathy. $J$ Vet Intern Med. 2004;18(2):165-175.

31. Chen D, Jefferson B, Harvey SJ, et al. Cyclosporine A slows the progressive renal disease of Alport syndrome (X-linked hereditary nephritis): results from a canine model. J Am Soc Nephrol. 2003;14(3): 690-698.

32. Lees GE, Wilson PD, Helman RG, Homco LD, Frey MS. Glomerular ultrastructural findings similar to hereditary nephritis in four English cocker spaniels. J Vet Intern Med. 1997;11(2):80-85.

33. Lees GE, Helman RG, Homco LD, Millichamp NJ, Hunter JF, Frey MS Early diagnosis of familial nephropathy in English cocker spaniels J Am Anim Hosp Assoc. 1998;34(3):189-195.

34. Lees GE, Helman RG, Kashtan CE, et al. A model of autosomal recessive Alport syndrome in English cocker spaniel dogs. Kidney Int. 1998;54(3):706-719.

35. Davidson AG, Bell RJ, Lees GE, Kashtan CE, Davidson GS, Murphy KE. Genetic cause of autosomal recessive hereditary nephropathy in the English cocker spaniel. J Vet Intern Med. 2007;21(3): 394-401.

36. Nowend KL, Starr-Moss AN, Lees GE, et al. Characterization of the genetic basis for autosomal recessive hereditary nephropathy in the English Springer Spaniel. J Vet Intern Med. 2012;26(2):294-301.

37. Hood JC, Savige J, Hendtlass A, Kleppel MM, Huxtable CR, Robinson WF. Bull terrier hereditary nephritis: A model for autosomal dominant Alport syndrome. Kidney Int. 1995;47(3):758-765.

38. Hood JC, Robinson WF, Clark WF, et al. Proteinuria as an indicator of early renal disease in bull terriers with hereditary nephritis. J Small Anim Pract. 1991;32(5):241-248.

39. Hood JC, Savige JA, Dowling J, et al. Ultrastructural appearance of renal and other basement membranes in the bull terrier model of autosomal dominant hereditary nephritis. Am J Kidney Dis. 2000;36(2): 378-391.

40. Hood JC, Dowling J, Bertram JF, et al. Correlation of histopathological features and renal impairment in autosomal dominant Alport syndrome in Bull terriers. Nephrol Dial Transplant. 2002;17(11):1897-1908.

41. Hood JC, Huxtable C, Naito I, Smith C, Sinclaire R, Savige J. A novel model of autosomal dominant Alport syndrome in Dalmatian dogs. Nephrol Dial Transplant. 2002;17(12):2094-2098.

42. Pescucci C, Mari F, Longo I, et al. Autosomal-dominant Alport syndrome: Natural history of a disease due to COL $4 A 3$ or COL $4 A 4$ gene. Kidney Int. 2004;65(5):1598-1603.

43. Picut CA, Lewis RM. Juvenile renal disease in the Doberman pinscher: Ultrastructural changes of the glomerular basement membrane. J Comp Pathol. 1987;97(5):587-596.

44. Rha JY, Labato MA, Ross LA, Breitschwerdt E, Alroy J. Familial glomerulonephropathy in a litter of beagles. J Am Vet Med Assoc. 2000; 216(1):46-50.

45. Wakamatsu N, Surdyk K, Carmichael KP, Brown CA. Histologic and ultrastructural studies of juvenile onset renal disease in four Rottweiler dogs. Vet Path. 2007;44(1):96-100.

46. Littman MP, Dambach DM, Vaden SL, Giger U. Familial protein-losing enteropathy and protein-losing nephropathy in soft-coated wheaten terriers: 222 cases (1983-1997). J Vet Intern Med. 2000;14(1):68-80.

47. Vaden SL, Giger U, Spaulding K, et al. Inheritance of protein-losing enteropathy and nephropathy of Soft Coated Wheaten Terriers [abstract]. $J$ Vet Intern Med. 2002;16(3):352.

48. Vaden SL, Littman MP, Cianciolo RE. Familial renal disease in softcoated wheaten terriers. J Vet Emerg Crit Care. 2013;23(2):174-183.

49. Afrouzian M, Vaden SL, Harris T, Hogan S, Falk RJ, Jennette JC. Immune complex mediated proliferative and sclerosing glomerulonephritis in Soft Coated Wheaten Terriers (SCWT): Is this an animal model of IgA nephropathy or IgM mesangial nephropathy? [abstract] J Am Soc Nephrol. 2001;12:670A.
50. Vaden SL, Jensen W, Longhofer S, Simpson DF. Longitudinal study of microalbuminuria in soft-coated wheaten terriers [abstract]. JVet Intern Med. 2001;15(3):300.

51. LeVine DN, Zhang DW, Harris T, Vaden SL. The use of pooled vs serial urine samples to measure urine protein:creatinine ratios. Vet Clin Pathol. 2010;39(1):53-56.

52. Vaden SL, Hammerberg B, Davenport DJ, et al. Food hypersensitivity reactions in soft-coated wheaten terriers with protein-losing enteropathy or protein-losing nephropathy or both: gastroscopic food sensitivity testing, dietary provocation, and fecal immunoglobulin E. J Vet Intern Med. 2000;14(1):60-67.

53. Vaden SL, Sellon RK, Melgarejo LT, et al. Evaluation of intestinal permeability and gluten sensitivity in soft-coated wheaten terriers with familial protein-losing enteropathy, protein-losing nephropathy, or both Am J Vet Res. 2000;61(5):518-524.

54. Allenspach K, Lomas B, Wieland B, et al. Evaluation of perinuclear anti-neutrophilic cytoplasmic autoantibodies as an early marker of protein-losing enteropathy and protein-losing nephropathy in Soft Coated Wheaten Terriers. Am J Vet Res. 2008;69(10):1301-1304.

55. Wieland B, Summers JF, Häsler B, Mancho-Alonso C, Craig A, Allenspach K. Prevalence of perinuclear antineutrophilic cytoplasmic autoantibodies in serum of healthy Soft Coated Wheaten Terriers in the United Kingdom. Am J Vet Res. 2012;73(3):404-408.

56. Nash AS, Kelly DF, Gaskell CJ. Progressive renal disease in soft-coated wheaten terriers: possible familial nephropathy. J Small Anim Pract. 1984;25(8):479-487.

57. Eriksen K, Grondalen J. Familial renal disease in soft-coated wheaten terriers. J Small Anim Pract. 1984;25(8):489-500.

58. Nash AS, Creswick JA. Familial nephropathy in soft-coated wheaten terriers. Vet Rec. 1988;123(25):654-655.

59. Littman MP, Wiley CA, Raducha MG, Henthorn PS. Glomerulopathy and mutations in NPHS1 and KIRREL2 in soft-coated Wheaten Terrier dogs. Mamm Genome. 2013;24(3-4):119-126.

60. Littman MP, Raducha MG, Henthorn PS. Prevalence of variant alleles associated with protein-losing nephropathy in Soft Coated Wheaten Terriers [abstract]. J Vet Intern Med. 2013;27(3):736.

61. Littman MP, Raducha MG, Henthorn PS. Prevalence of variant alleles associated with protein-losing nephropathy in Airedale Terriers [abstract]. J Vet Intern Med. 2014;28(4):1366-1367.

62. Rørtveit R, Lingaas F, Bønsdorff T, et al. A canine autosomal recessive model of collagen type III glomerulopathy. Lab Invest. 2012;92(10): 1483-1491.

63. Rørtveit R, Eggertsdóttir AV, Thomassen R, Lingaas F, Jansen JH A clinical study of canine collagen type III glomerulopathy. BMC Vet Res. 2013;9:e218:1-8.

64. Koeman JP, Biewenga WJ, Gruys E. Proteinuria associated with glomerulosclerosis and glomerular collagen formation in three Newfoundland dog littermates. Vet Pathol. 1994;31(2):188-193.

65. Segev G, Cowgill LD, Jessen S, Berkowitz A, Mohr CF, Aroch I. Renal amyloidosis in dogs: a retrospective study of 91 cases with comparison of the disease between Shar-Pei and non-Shar-Pei dogs. J Vet Intern Med. 2012;26(2):259-268.

66. DiBartola SP, Tarr MJ, Webb DM, Giger U. Familial renal amyloidosis in Chinese Shar Pei dogs. J Am Vet Med Assoc. 1990;197(4):483-487.

67. Olsson M, Meadows JRS, Truvé K, et al. A novel unstable duplication upstream of $H A S 2$ predisposes to a breed-defining skin phenotype and a periodic fever syndrome in Chinese Shar-Pei dogs. PLoS Genet. 2011;7(3):e1001332:1-11.

68. Bowles MH, Mosier DA. Renal amyloidosis in a family of beagles J Am Vet Med Assoc. 1992;201(4):569-574.

69. Mason NJ, Day MJ. Renal amyloidosis in related English foxhounds. J Small Anim Pract. 1996;37(6):255-260.

70. Littman MP. State-of-the-Art-Review: Lyme nephritis. JVet Emerg Crit Care. 2013;23(2):163-173.

71. Littman MP, Goldstein RE, Labato MA, Lappin MR, Moore GE. ACVIM small animal consensus statement on Lyme disease in dogs: Diagnosis, treatment, and prevention. J Vet Intern Med. 2006;20(2):422-434. 
72. Dambach DM, Smith CA, Lewis RM, Van Winkle TJ. Morphologic, immunohistochemical, and ultrastructural characteristics of a distinctive renal lesion in dogs putatively associated with Borrelia burgdorferi infection: 49 cases (1987-1992). Vet Pathol. 1997;34(2):85-96.

73. Chou J, Wunschmann A, Hodzic E, Borjesson DL. Detection of Borrelia burdorferi DNA in tissues from dogs with presumptive Lyme borreliosis. J Am Vet Med Assoc. 2006;229(8):1260-1265.

74. Goldstein RE, Cordner AP, Sandler JL, Bellohusen BA, Erb HN. Microalbuminuria and comparison of serologic testing for exposure to Borrelia burgdorferi in nonclinical Labrador and Golden Retrievers. J Vet Diagn Invest. 2007;19(3):294-297.

75. Reusch C, Hoerauf A, Lechner J, et al. A new familial glomerulonephropathy in Bernese mountain dogs. Vet Rec. 1994;134(16):411-415.

76. Minkus G, Breuer W, Wanke R, et al. Familial nephropathy in Bernese Mountain Dogs. Vet Pathol. 1994;31(4):421-428.

77. Gerber B, Eichenberger S, Haug K, Wittenbrink MM, Reusch CE. Association of urine protein excretion and infection with Borrelia burgdorferi sensu lato in Bernese Mountain dogs. Vet J. 2009;182(3):487-488.

78. Gerber B, Haug K, Eichenberger S, Reusch CE, Wittenbrink MM. Follow up of Bernese Mountain dogs and other dogs with serologically diagnosed Borrelia burgdorferi infection: What happens to seropositive animals? BMC Vet Res. 2009; 18:1-8.

79. Gaskin AA, Schantz P, Jackson J, et al. Visceral leishmaniasis in a New York foxhound kennel. J Vet Intern Med. 2002;16(1):34-44.

80. Zatelli A, Borgarelli M, Santilli R, et al. Glomerular lesions in dogs infected with Leishmania organisms. Am J Vet Res. 2003;64(5): 558-561.

81. Poli A, Abramo F, Mancianti F, Nigro M, Pieri S, Bionda A. Renal involvement in canine leishmaniasis. A light microscopic, immunohistochemical and electron-microscopy study. Nephron. 1991;57(4): 444-452.

82. Costa FAL, Goto H, Saldanha LCB, et al. Histopathologic patterns of nephropathy in naturally acquired canine visceral leishmaniasis. Vet Pathol. 2003;40(6):677-684.

83. Breitschwerdt EB. Immunoproliferative enteropathy of Basenjis. Semin Vet Med Surg (Small Anim). 1992;7(2):153-161.

84. Giger U, Werner LL, Millichamp NJ, Gorman NT. Sulfadiazine-induced allergy in six Doberman Pinschers. J Am Vet Med Assoc. 1985;186(5): 479-484.

85. Vasilopulos RJ, Mackin A, Lavergne SN, Trepanier LA. Nephrotic syndrome associated with administration of sulfadimethoxine/ormetoprim in a dobermann. J Small Anim Pract. 2005;46(5):232-236.

86. Trepanier LA. Idiosyncratic toxicity associated with potentiated sulfonamides in the dog. J Vet Pharmacol Ther. 2004;27(3):129-138.

87. Codner EC, Caceci T, Saunders GK, et al. Investigation of glomerular lesions in dogs with acute experimentally induced Ehrlichia canis infection. Am J Vet Res. 1992;53(12):2286-2291.

88. Codner EC, Maslim WR. Investigation of renal protein loss in dogs with acute experimentally induced Ehrlichia canis infection. Am J Vet Res. 1992;53(3):294-299.

89. Nyindo M, Huxsoll DL, Ristic M, et al. Cell-mediated and humoral immune responses of German shepherd dogs and beagles to experimental infection with Ehrlichia canis. Am J Vet Res. 1980;41(2):250-254.

90. Castro MB de, Machado RZ, Aquino LPCT de, Alessi AC, Cost MT. Experimental acute canine monocytic ehrlichiosis: clinicopathological and immunopathological findings. Vet Parasitol. 2004;119(1):73-86.
91. Cork LC, Morris JM, Olson JL, Krakowka S, Swift AJ, Winkelstein JA. Membranoproliferative glomerulonephritis in dogs with a genetically determined deficiency of the third component of complement. Clin Immunol Immunopathol. 1991;60(3):455-470.

92. Ameratunga R, Winkelstein JA, Brody L, et al. Molecular analysis of the third component of canine complement (C3) and identification of the mutation responsible for hereditary canine $\mathrm{C} 3$ deficiency. J Immunol. 1998;160(6):2824-2830.

93. Casal ML, Dambach DM, Meister T, Jezyk PF, Patterson DF, Henthorn PS. Familial glomerulonephropathy in the Bullmastiff. Vet Pathol. 2004;41(4):319-325.

94. Wilcock BP, Patterson JM. Familial glomerulonephritis in Doberman Pinscher dogs. Can Vet J. 1979;20(9):244-249.

95. Lavoué R, van der Lugt JJ, Day MJ, et al. Progressive juvenile glomerulonephropathy in 16 related French Mastiff (Bordeaux) dogs. J Vet Intern Med. 2010;24(2):314-322.

96. Carpenter JL, Andelman NC, Moore FM, King NW Jr. Idiopathic cutaneous and renal glomerular vasculopathy of Greyhounds. Vet Pathol. 1988;25(6):401-407.

97. Hertzke DM, Cowan LA, Schoning P, Fenwick BW. Glomerular ultrastructural lesions of idiopathic cutaneous and renal glomerular vasculopathy of greyhounds. Vet Pathol. 1995;32(5):451-459.

98. Cowan LA, Hertzke DM, Fenwick BW, Andreasen CB. Clinical and clinicopathologic abnormalities in Greyhounds with cutaneous and renal glomerular vasculopathy: 18 cases (1992-1994). J Am Vet Med Assoc. 1997;210(6):789-793.

99. Bjotvedt G, Hendricks GM, Brandon TA. Hemodynamic basis of renal arteriosclerosis in young greyhounds. Lab Anim Sci. 1988;38(1): $62-67$.

100. Morton LD, Sanecki RK, Gordon DE, Sopiarz RL, Bell JS, Sakas PS. Juvenile renal disease in miniature schnauzer dogs. Vet Pathol. 1990;27(6):455-458.

101. Finco DR. Familial renal disease in Norwegian elkhound dogs: physiologic and biochemical examinations. Am JVet Res. 1976;37(1): 87-91.

102. Finco DR, Duncan JD, Crowell WA, Hulsey ML. Familial renal disease in Norwegian elkhound dogs: morphologic examinations. Am J Vet Res. 1977;38(7):941-947.

103. Wiersma AC, Millon LV, van Dongen AM, van Oost BA, Bannasch DL. Evaluation of canine COL4A3 and COL4A4 as candidates for familial renal disease in the Norwegian Elkhound. $J$ Hered. 2005;96(7): 739-744

104. McKay LW, Seguin MA, Ritchey JW, Levy JK. Juvenile nephropathy in two related Pembroke Welsh corgi puppies. J Small Anim Pract. 2004;45(11):568-571.

105. Cook SM, Dean DF, Golden DL, Wilkinson JE, Means TL. Renal failure attributable to atrophic glomerulopathy in four related rottweilers. J Am Vet Med Assoc. 1993;202(1):107-109.

106. Gharahkhani P, O’Leary CA, Kyaw-Tanner M, Sturm RA, Duffy DL. A non-synonymous mutation in the canine $P k d l$ gene is associated with autosomal dominant polycystic kidney disease in Bull Terriers. PLoS One. 2011;6(7):e22455:1-8.
Advances in Genomics and Genetics

\section{Publish your work in this journal}

Advances in Genomics and Genetics is an international, peer reviewed, open access journal that focuses on new developments in characterizing the human and animal genome and specific gene expressions in health and disease. Particular emphasis will be given to those studies that elucidate genes, biomarkers and targets in the development of new or improved therapeutic
Dovepress

interventions. The journal is characterized by the rapid reporting of reviews, original research, methodologies, technologies and analytics in this subject area. The manuscript management system is completely online and includes a very quick and fair peer-review system. Visit http://www.dovepress.com testimonials.php to read real quotes from published authors. 